\title{
COMMENTARY
}

\section{Goal-directed or goal-misdirected - how should we interpret the literature?}

\author{
Anthony M Roche* and Timothy E Miller \\ See related review by Lees et al., http://ccforum.com/content/13/5/231
}

\begin{abstract}
Goal-directed therapy (GDT) can be a vague term, meaning different things to different people and, depending on the clinical environment, sometimes even different things to the same person. It can refer to perioperative fluid management, clinicians driving oxygen delivery to supramaximal values, early treatment of sepsis in the emergency department, and even to restriction of perioperative crystalloids with the goal of maintaining preadmission body weight. Understandably, strong opinions about GDT vary; some clinicians consider it essential for perioperative care, others completely ineffective in critically ill patients. This commentary aims to further position the excellent review by Lees and colleagues in the context of the critical care and perioperative setting.
\end{abstract}

Given the confusion and strong opinions surrounding goal-directed therapy (GDT), Lees and colleagues [1] have done a commendable job of clearly defining GDT and how it pertains to each clinical setting as well as separately examining the individual bodies of relevant literature. The authors separate the physiologic and pathophysiologic discussion of both the perioperative and septic patient populations, thus contextualizing different approaches to both volume and hemodynamic GDT. Despite the encouraging body of literature in the early days of oxygen-targeted approaches to early GDT (oxygen delivery $\left[\mathrm{DO}_{2}\right]$ of greater than $600 \mathrm{~mL} / \mathrm{min}$ per $\mathrm{m}^{2}$ ) [2-4], more recent studies have not confirmed these results $[5,6]$. Much speculation and controversy surrounds this technique, where it appears that no benefit, if not worse outcomes, are being observed in patients with established

*Correspondence: tony.roche@duke.edu

Department of Anesthesiology, DUMC 3094, Duke University Medical Center, Durham, NC, 27710, USA sepsis. Conversely, measurable benefits have been observed in the perioperative setting, though not in all of the published studies.

Recent interest surrounds the work of Rivers and colleagues [7], in which a significant mortality reduction was observed in patients admitted with septic shock to the emergency department. Patients were randomly assigned to either standard-of-care treatment or a multifaceted early GDT algorithm, incorporating volume optimization, blood, and inotropes. Major criticisms of the study are that it was single-center with relatively small numbers and with a high mortality rate in the control group (considering the APACHE II [Acute Physiology and Chronic Health Evaluation II] scores), and no subsequent studies have yet replicated these results. A large multicenter randomized controlled study (studying almost 2,000 patients), called the ProCESS (Protocolized Care for Early Septic Shock) Study (ClinicalTrials.gov number NCT00510835), is currently under way, examining this technique in greater detail.

The major controversy in the perioperative setting is whether to maximize stroke volume or to restrict fluids. These bodies of literature appear to be completely contradictory in their techniques, usually leaving the clinician confused. With a number of randomized controlled trials published, there is little doubt that stroke volume optimization is a good thing, albeit that all published studies are single-center efforts [8]. The restrictive studies have all used different strategies for restricting the total volume of fluids administered, with results ranging from improved outcomes through no difference to worse outcomes with restrictive practice $[9,10]$. It is extremely unfortunate that the name 'restriction' was chosen early on in this body of literature as the true technique guides a relative fluid restriction to prior techniques rather than an absolute restriction in volume. A more suitable term is 'avoidance of crystalloid excess', which is the key to improving outcomes. These two approaches can be complementary, when a judicious volume of crystalloid is administered (that is, 'restrictive' approach) combined with a stroke volume-targeted 
amount of colloid ('goal-directed'), depending on the patient and type of surgery.

This all leaves us wondering what technology we should use. For pure volume optimization, the esophageal Doppler monitor has the largest body of evidence to guide its use [11-13]. Its relatively steep and difficult learning curve has probably been its Achilles heel, slowing adoption somewhat; however, its incorporation into the Enhanced Recovery After Surgery (ERAS) program is currently a strong driving force for renewed interest. An alternative approach is arterial waveform-derived cardiac output monitoring, in which the intravascular volume responsiveness indices (for example, stroke volume variation and pulse pressure variation) appear to be capable of providing acceptable data for guiding fluid management in mandatory ventilated patients [14]. It is important to note that there are currently only a couple of studies showing that oxygen-targeted approaches [15] or volume optimization [16] with these monitors improves outcomes. The current distinct lack of pertinent research in this area makes difficult any recommendation regarding universal adoption of these waveform-based technologies.

The big question is: what should we do, or how should we go about early GDT? We believe that carefully managed crystalloids, following the 'restrictive' principles and accounting for crystalloid needs, is the first important step. Early, simple algorithmic, stroke volumetargeted colloid fluid administration is the second important step, guiding both the administration and the pausing of colloid intravenous fluids.

So should we then use oxygen-targeted approaches? Although the groups of Shoemaker [2], Boyd [3], Wilson [4], and Pearse [15] have all shown improved outcomes with these types of approaches, it is the dissention of groups showing no difference or worse outcomes that has clouded the water $[5,6]$. Despite unfavorable results in patients with advanced sepsis, it is likely that in addition to the above-mentioned fluid management, the high-risk perioperative patient will benefit from such approaches. The target $\mathrm{DO}_{2}$ of $600 \mathrm{~mL} / \mathrm{min}$ per $\mathrm{m}^{2}$ of Shoemaker and colleagues [2] could still be ideal, but it seems prudent to individualize each patient's target based on their specific physiologic profile, something we should gain greater understanding of over the next few years, with cardiopulmonary exercise testing driving the type and extent of therapy. Furthermore, we currently have no useful monitor of tissue 'well-being', which could be invaluable in the delivery of GDT. Tissue oximetry may be of benefit but is still a long way from being a routine monitor.

Clearly, our practice needs to be guided to optimizing tissues at risk (for example, the gut). When these tissues are struggling, our therapy needs to be escalated to meet the need and resuscitate these tissues. Should the risk have endured too long and tissues suffer irreparable damage, the final word belongs to Shoemaker. Following the publication of a large GDT study by Gattinoni and colleagues [6] in 1995, Shoemaker [17] wrote a letter to the editor, stating: '...Gattinoni et al., like Hayes et al., have done us a service by pointing out the limitations of our approach, which clearly does not prevent organ failure and death in patients who already have established organ failure. We concur that it is impossible to resuscitate dead cells and failed organs, even with oxygen'.

\section{Abbreviations}

$\mathrm{DO}_{2}$, oxygen delivery; GDT, goal-directed therapy.

\section{Competing interests}

AR has received research support and consulting honorarium from Edwards Lifesciences LLC (Irvine, CA, USA), lecturing honoraria from LiDCO Ltd. (Cambridge, UK) and Fresenius Kabi AG (Bad Homburg, Germany), and consulting honorarium from Masimo Corporation (Irvine, CA, USA). TM has received lecturing honoraria from LiDCO Ltd., Fresenius Kabi AG, and Hospira, Inc. (Lake Forest, IL, USA).

\section{Authors' information}

AR is an attending anesthesiologist at Duke University Medical Center (DUMC) and is assisting in the creation of an ERAS (enhanced recovery after colorectal surgery) program at DUMC. He was the medical director of the 1st and 2nd Great American Fluid Debates (2008 and 2009) and is co-director with Monty Mythen of the Great Fluid Debates (London, UK) and the 2010 Great Canadian Fluid Debate. He is also an attending critical care physician of the Durham Veteran's Affairs Hospital Surgical Intensive Care Unit. Besides his involvement in global health initiatives, he has interests in hemodynamic monitoring, intravenous fluids, blood conservation, and endothelial dysfunction. TM is an attending anesthesiologist at DUMC and the anesthesiology lead for the creation of the DUMC ERAS program. His areas of clinical interest are major vascular, major general, and liver transplantation anesthesia. He also has significant scientific interests in hemodynamic monitoring, intravenous fluids, and enhanced recovery after surgery.

\section{Published: 10 March 2010}

\section{References}

1. Lees N, Hamilton M, Rhodes A: Clinical review: Goal-directed therapy in high risk surgical patients. Crit Care 2009, 13:231.

2. Shoemaker WC, Appel PL, Kram HB, Waxman K, Lee TS: Prospective trial of supranormal values of survivors as therapeutic goals in high-risk surgical patients. Chest 1988, 94:1176-1186.

3. Boyd O, Grounds RM, Bennett ED: A randomized clinical trial of the effect of deliberate perioperative increase of oxygen delivery on mortality in highrisk surgical patients. JAMA 1993, 270:2699-2707.

4. Wilson J, Woods I, Fawcett J, Whall R, Dibb W, Morris C, McManus E: Reducing the risk of major elective surgery: randomised controlled trial of preoperative optimisation of oxygen delivery. BMJ 1999, 318:1099-1103.

5. Hayes MA, Timmins AC, Yau EH, Palazzo M, Hinds CJ, Watson D: Elevation of systemic oxygen delivery in the treatment of critically ill patients. NEngl J Med 1994, 330:1717-1722

6. Gattinoni L, Brazzi L, Pelosi P, Latini R, Tognoni G, Pesenti A, Fumagalli R: A trial of goal-oriented hemodynamic therapy in critically ill patients. SvO2 Collaborative Group. N Engl J Med 1995, 333:1025-1032.

7. Rivers E, Nguyen B, Havstad S, Ressler J, Muzzin A, Knoblich B, Peterson E, Tomlanovich M: Early goal-directed therapy in the treatment of severe sepsis and septic shock. NEngl J Med 2001, 345:1368-1377.

8. Giglio MT, Marucci M, Testini M, Brienza N: Goal-directed haemodynamic therapy and gastrointestinal complications in major surgery: a metaanalysis of randomized controlled trials. Br J Anaesth 2009, 103:637-646.

9. Brandstrup B, Tønnesen H, Beier-Holgersen R, Hjortsø E, Ørding H, LindorffLarsen K, Rasmussen MS, Lanng C, Wallin L, Iversen LH, Gramkow CS, Okholm M, Blemmer T, Svendsen PE, Rottensten HH, Thage B, Riis J, Jeppesen IS, Teilum D, Christensen AM, Graungaard B, Pott F; Danish Study Group on 
Perioperative Fluid Therapy: Effects of intravenous fluid restriction on postoperative complications: comparison of two perioperative fluid regimens: a randomized assessor-blinded multicenter trial. Ann Surg 2003, 238:641-648.

10. Holte K, Klarskov B, Christensen DS, Lund C, Nielsen KG, Bie P, Kehlet H: Liberal versus restrictive fluid administration to improve recovery after laparoscopic cholecystectomy: a randomized, double-blind study. Ann Surg 2004, 240:892-899.

11. Mythen MG, Webb AR: Perioperative plasma volume expansion reduces the incidence of gut mucosal hypoperfusion during cardiac surgery. Arch Surg 1995, 130:423-429.

12. Noblett SE, Snowden CP, Shenton BK, Horgan AF: Randomized clinical trial assessing the effect of Doppler-optimized fluid management on outcome after elective colorectal resection. Br J Surg 2006, 93:1069-1076.

13. Wakeling HG, McFall MR, Jenkins CS, Woods WG, Miles WF, Barclay GR, Fleming SC: Intraoperative oesophageal Doppler guided fluid management shortens postoperative hospital stay after major bowel surgery. Br J Anaesth 2005, 95:634-642.
14. Michard F, Lopes MR, Auler JO Jr:: Pulse pressure variation: beyond the fluid management of patients with shock. Crit Care 2007, 11:131.

15. Pearse R, Dawson D, Fawcett J, Rhodes A, Grounds RM, Bennett ED: Early goal-directed therapy after major surgery reduces complications and duration of hospital stay. A randomised, controlled trial [ISRCTN38797445]. Crit Care 2005, 9:R687-693.

16. Lopes MR, Oliveira MA, Pereira VO, Lemos IP, Auler JO Jr., Michard F: Goaldirected fluid management based on pulse pressure variation monitoring during high-risk surgery: a pilot randomized controlled trial. Crit Care 2007, 11:R100

17. Shoemaker WC: Goal-oriented hemodynamic therapy. N Engl J Med 1996, 334:799-800; author reply 800 .

doi:10.1186/cc8884

Cite this article as: Roche AM, Miller TE: Goal-directed or goal-misdirected how should we interpret the literature? Critical Care 2010, 14:129. 